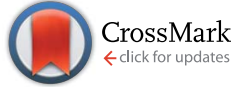

Cite this: J. Mater. Chem. A, 2015, 3 , 5628

Received 3rd December 2014 Accepted 9th February 2015

DOI: $10.1039 / c 4 t a 06625 a$

www.rsc.org/MaterialsA

\section{Parametric investigation of room-temperature fluoride-ion batteries: assessment of electrolytes, Mg-based anodes, and $\mathrm{BiF}_{3}$-cathodes $\dagger$}

\begin{abstract}
Fabienne Gschwind $^{\star a b}$ and Joshua Bastien ${ }^{\mathrm{ab}}$
Little is known about room-temperature fluoride-ion batteries (RT FiBs), and no investigations that have varied their potential electrolytes, cathode preparations, or anode materials have been reported. In this publication, an overview of our recent investigations of these parameters for the purposes of improving the discharge capacities of RT FiBs is provided. The poly(ethylene glycol) (PEG)-based electrolytes in these systems function as ligands for fluoride ions. The impact of the increasing ligand length on battery capacity was investigated. Using Mg as an anode, different anode builds (e.g., foil or pressed pellets), as well as several composite anodes (e.g., $\mathrm{Mg} / \mathrm{MgF}_{2}$ ) were tested. Furthermore the difference between cathodes prepared as hand-spread slurries or by spray-coating was investigated. Additionally the impact of using a water-soluble binder was examined. Finally, problems due to the leaching of alkaline (and/or alkaline earth) metal ions from the glass-fiber separators into the electrolyte were considered. In summary, it was demonstrated that FiBs will work using magnesium anodes, and that the capacities of such batteries are sensitive to every small change in their components.
\end{abstract}

\section{Introduction}

Fluoride-ion batteries (FiBs) are based on anion transport using fluoride or bifluoride ${ }^{1}$ ions as shuttle agents.

Depending on the materials used for the construction of a FiB, an energy density of about $5000 \mathrm{~W} \mathrm{~h} \mathrm{~L}^{-1}$ could be obtained. ${ }^{2}$ These high capacities and energy densities are possible because of the extraordinary electronegativity of fluorine. When fluorine reacts with metals to form a metal fluoride a large change in the free energy is observed, which leads to high theoretical voltages in electrochemical cells. ${ }^{3}$ To date, only a handful of papers have provided insight into this new type of battery, ${ }^{2,3}$ and only one paper discusses room-temperature fluoride batteries with a liquid electrolyte, ${ }^{1}$ although a patent has claimed the use of liquid electrolytes. ${ }^{4}$

The general working principle for the FiB is based on the reduction of the cathodic material and the oxidation of the anodic material via fluoride-ion transport through the electrolyte. For example, $\mathrm{Mg}$ is oxidized to $\mathrm{MgF}_{2}$, releasing two electrons, which travel via an external circuit to the cathode. There, $\mathrm{BiF}_{3}$ is reduced to metallic bismuth, releasing three fluoride

${ }^{a}$ Helmholtz-Institute Ulm (HIU), Albert-Einstein-Allee 11, 89081 Ulm, Germany. E-mail: fabienne.gschwind@kit.edu; Fax: +49 73150 34299; Tel: +49 7315034212 ${ }^{b}$ Karlsruhe Institute of Technology (KIT), Hermann-von-Helmholtz-Platz 1, 76344 Eggenstein-Leopoldshafen, Germany. Tel: +4972160828972

$\dagger$ Electronic supplementary information (ESI) available. See DOI: 10.1039/c4ta06625a ions into the electrolyte, which assures the ionic transport of the fluoride species (Fig. 1).

In our previous study of a FiB system, an electrolyte based on polyethylene glycol with coordinated ammonium bifluoride molecules was investigated. Our proposed mode of binding is depicted in Fig. 2.

The battery also used lithium foil as the anode and ${\mathrm{a} \mathrm{BiF}_{3}-}^{-}$ carbon composite as the cathode. Unfortunately, the performance of this system was not satisfactory.

For example, as a cathode material, the theoretical capacity of $\mathrm{BiF}_{3}$ is not ideal, ${ }^{5}$ and its high mass diminishes the effective capacity of the cell, which is calculated based on the active mass of the cathode. The advantage of using $\mathrm{BiF}_{3}$ is that elemental bismuth is easily recognized by powder X-ray diffractometry

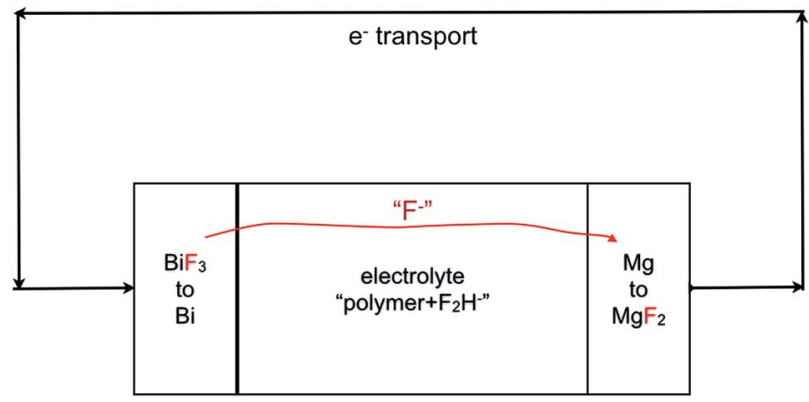

Fig. 1 Fluoride-ion battery configuration. Discharge process for the $\mathrm{BiF}_{3}$ cathode and $\mathrm{Mg}$ anode system. 


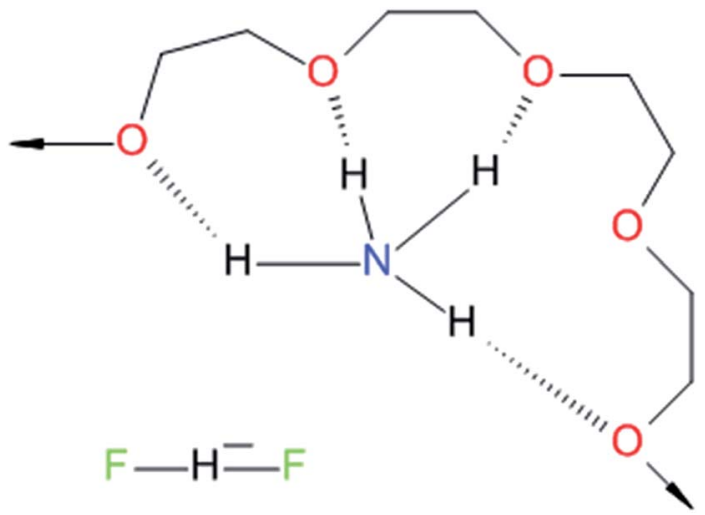

Fig. 2 Ligand-binding mode in electrolyte system. Proposed coordination mode of $\mathrm{NH}_{4}^{+}$with a polyethylene glycol ligand.

(PXRD); this accounts for our continued use of Bi in this study. Electrodes can be prepared in many different ways, such as by spreading slurries or by pressing. In preliminary tests, it was found that the method of preparation significantly impacts the efficiency of the battery. The slurry method of preparation requires the use of a polyvinylidene difluoride (PVDF) binder, whereas pellets do not. It is unclear if the PVDF binder inhibits fluoride transport in the battery, or if other binders such as carboxymethyl cellulose (CMC) would be better for preparing cathodes.

Until now, only lithium anodes have been used as the anode in RT-FiBs, whereas solid-state FiBs have used lanthanum- or cerium-based anodes. In our last publication, it was shown that lithium ions can migrate into the electrolyte and can contribute to the observed capacity. ${ }^{1}$ In this study, completely different anode materials, consisting of magnesium and magnesium composites were tested. In total five different systems were chosen: pure $\mathrm{Mg}$ pressed in pellets, $\mathrm{Mg}$ foil, a partially charged $\mathrm{Mg} / \mathrm{MgF}_{2}$-composite, ${ }^{6,7}$ a partially charged $\mathrm{Mg} / \mathrm{KF}$-composite, and lastly, another composite with polyaniline (PANI) emeraldine base. ${ }^{4}$

In our last paper, an electrolyte based on methylated PEG6000 and ammonium bifluoride was presented. Ammonium cations are "wrapped" (coordinated) into the PEG molecules, and the resulting "giant cation" forces the bifluoride anion to remain in solution. This type of electrolyte proved to be stable and HF formation could not be detected by thermogravimetric analysis (TGA) upon heating the compound. ${ }^{1}$ Therefore, the fluoride-doped PEG matrixes were retained and our attention was turned to the impact of ligand size (glycol chain length).

Furthermore, up until now, the electrolyte was prepared with a solid material, PEG6000, which resulted in a finished solid electrolyte. In order to be able to use it in our battery system, the electrolyte first had to be dissolved in a solvent. Therefore, electrolyte systems with shorter chain lengths, which are naturally liquid, were investigated more closely.

At this time, our focus is on primary cells in which only the first discharge is investigated. Charging is problematic due to the passivation of the $\mathrm{Mg}$ anode and the low solubility of $\mathrm{MgF}_{2}$.
This will be discussed in greater detail below. In this publication, new results obtained for these different systems are presented, a new lithium-free room-temperature fluoride battery is reported and based on this results some inferences and conclusions about FiBs are drawn.

\section{Results and discussion}

\section{Electrolyte}

The three new electrolytes tetraglyme $\cdot \mathrm{NH}_{4} \mathrm{~F}_{2} \mathrm{H}$ (TG), higlyme $\cdot \mathrm{NH}_{4} \mathrm{~F}_{2} \mathrm{H}$ (Hi), PEO600 000 $\mathrm{NH}_{4} \mathrm{~F}_{2} \mathrm{H}$ (PEO) and the already published PEG6000 $\cdot \mathrm{NH}_{4} \mathrm{~F}_{2} \mathrm{H}$ (PEG6000) based on polyethers with differing chain lengths (relative chain length; TG $<$ $\mathrm{Hi}<\mathrm{PEG6000}<\mathrm{PEO}$ ), were prepared as described in the Experimental section. Each exhibited a double ${ }^{19} \mathrm{~F}$ NMR peak at about $-152 \mathrm{ppm}$, as has been previously observed. ${ }^{1}$ We noticed that the bifluoride signal of the compound PEO is much weaker than the other, possibly due to a poor doping of $\mathrm{NH}_{4} \mathrm{~F}_{2} \mathrm{H}$ in the polymer network. The FTIR spectra of these materials, the large peak at $3090 \mathrm{~cm}^{-1}$ normally due to the $\mathrm{N}-\mathrm{H}$ stretch of $\mathrm{NH}_{4}{ }^{+}$was not observed, which indicates complexation of the cation in the polymer matrixes. ${ }^{1}$ In other regions, the three electrolytes are spectrally very similar and show almost the same peak patterns (ESI†). Thermal stability assessment by TGA-DSC shows that no HF or ammonia is released before the final decomposition temperatures (Fig. 3).

A weight loss was observed for compound PEO around $267{ }^{\circ} \mathrm{C}$, possibly due to decomposition of smaller polyethylene glycol components which are also present in the polymer blend.

Liquid electrolytes TG and Hi showed almost no conductivity in their native states (Fig. 4), but the incremental addition of MeCN dramatically increased their conductivity.

The undiluted electrolyte $\mathrm{Hi}$ had a conductivity of $3 \mu \mathrm{S} \mathrm{cm}^{-1}$, but dilution to $48 \%$ MeCN content resulted in a conductivity increase to $878 \mu \mathrm{S} \mathrm{cm}^{-1}$. For electrolyte TG, the value difference is even more impressive: $238 \mu \mathrm{S} \mathrm{cm}^{-1}$ for the pure solvent and $1960 \mu \mathrm{S} \mathrm{cm}^{-1}$ at $44 \%$ dilution with MeCN. Electrolyte PEO peaked at a conductivity of $20 \mu \mathrm{S} \mathrm{cm}^{-1}$ and is therefore not represented in the figure. The poor conductivity of PEO fits also

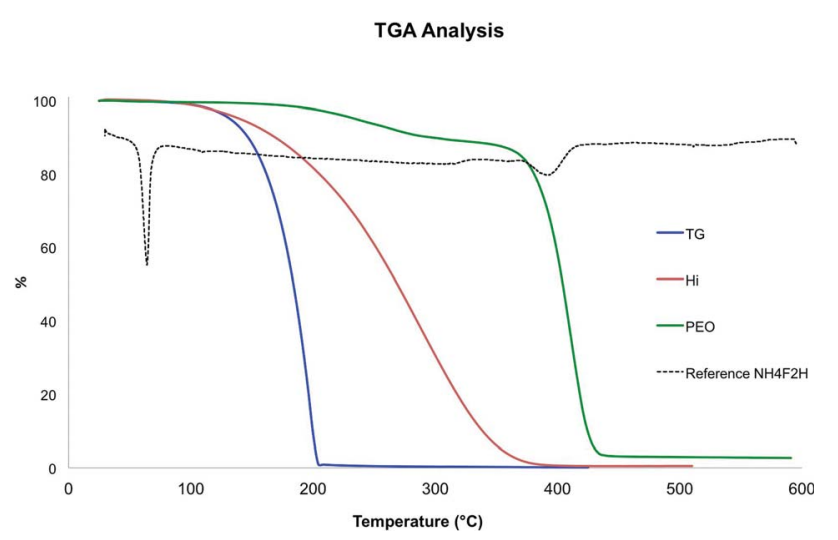

Fig. 3 Thermogravimetric analysis. TGA analysis of the three new electrolytes and the starting material, ammonium bifluoride. 
Conductivity of TG and $\mathrm{Hi}$ towards amount of MeCN

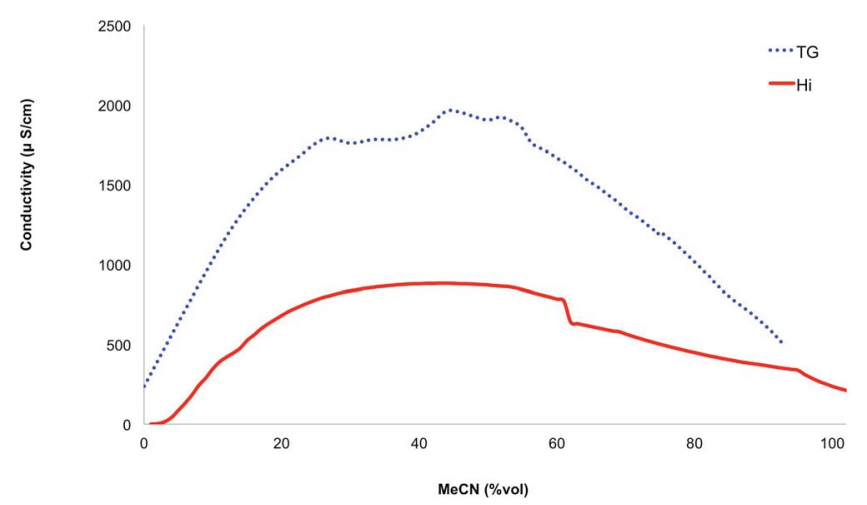

Fig. 4 Conductivity of liquid electrolytes $\mathrm{TG}$ and $\mathrm{Hi}$ as a function of MeCN content.

with the previous observation, that the doping procedure probably does not work as well for the very large polymer.

We propose that, in their undiluted states, the small polymers in higlyme and the tetraglyme oligomers form densely coordinated structures, which fix the ammonium cations as well as the bifluoride anions in a network. Upon addition of the solvent, the network is partially relaxed and frees enough ions to obtain a loosely coordinated system, ${ }^{\mathbf{8}, 9}$ allowing ionic conductivity (Fig. 5).

\section{$\mathrm{BiF}_{3}$ cathode preparation}

Next, the impact of different preparation methods and binders used in the cathode through a series of battery cells were explored. A main issue that was observed was reproducibility in the cell tests, which generally showed a difference in capacity between identically built cells. One problem was the cathode, which was typically prepared using a hand-spread slurry of $\mathrm{BiF}_{3} /$ $\mathrm{PVDF} / \mathrm{C}$ on a stainless steel collector. All the collectors were, therefore, unique and had different active material weights; also, the surfaces were never flat. To avoid these problems, we opted to spray coat the materials, and to avoid PVDF. The omission of the binder was sought for two reasons in particular: (i) to avoid using the toxic solvent NMP, and (ii) to remove the possible influence of PVDF on capacity, as suggested by preliminary tests. Therefore we opted to use sodium
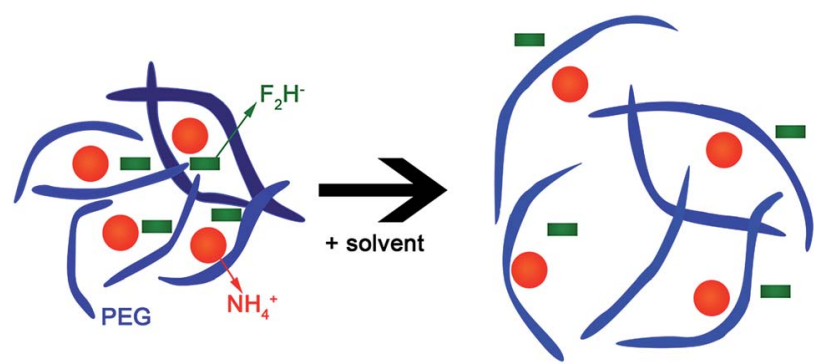

Fig. 5 Solvent effect on electrolyte. Swelling of the glyme oligomers to afford ion conductivity. carboxymethyl cellulose (CMC) as the binder due to the fact that it is water soluble, non-toxic, and sustainable. ${ }^{\mathbf{1 0 - 1 2}}$ The cathodic material was suspended in water and spray-coated on a stainless steel collector until a layer containing about $1 \mathrm{mg}$ of the material was obtained. The experiments were performed in Swage-lock cells as well as in a homemade multi-cell battery (ESI†). A piece of glass wool (Whatman) was used as the separator. The test cells were discharged with a standard current density of $1 \times 10^{-5} \mathrm{~A}$ at $25^{\circ} \mathrm{C}$.

Prior to the cell tests, the dried electrolytes TG, Hi, and PEO were combined with dimethyl carbonate (DMC) and acetonitrile (MeCN) in a $55: 10: 35$ vol\% ratio. ${ }^{19}$ F-NMR analysis of the as prepared electrolytes were performed. The fluoride peaks in ${ }^{19} \mathrm{~F}$ NMR remained almost unshifted but were considerably weaker due to the dilution (see ESI $\dagger$ ). The previously studied PEG6000 $\cdot \mathrm{NH}_{4} \mathrm{~F}_{2} \mathrm{H}$ (PEG6000) was prepared at a concentration of $0.05 \mathrm{M}$ similar to ref. 1 .

The liquid electrolytes TG and $\mathrm{Hi}$ (267 and $375 \mathrm{~mA} \mathrm{~h} \mathrm{~g}^{-1}$ ) exhibited the best initial discharge capacities (Fig. 6). Electrolyte PEG6000 (129 $\mathrm{mA} \mathrm{h} \mathrm{g}^{-1}$ ) provided a fairly good result, whereas the solid electrolyte PEO (66 $\mathrm{mA} \mathrm{h} \mathrm{g}^{-1}$ ) exhibited the worst capacity. XRD analysis of all the cathodes after cycling revealed the well-known bismuth peak, but no major changes on the cathode surface could be observed by SEM (ESI $\dagger$ ).

The use of lithium as an anode is known to be problematic due to the dissolution of Li ions in the electrolyte, ${ }^{1}$ which can contribute to capacity measurement errors. We strongly suspect that this occurred with liquid electrolyte TG, because the measured capacity was higher than the theoretical capacity

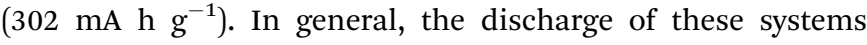
required more than 10 days. This extended time could have allowed more lithium ions to migrate into the electrolyte.

Furthermore, FiBs were proposed as alternative systems to Li-ion batteries, which prompted our interest in testing $\mathrm{Mg}$ anodes. Both bulk $\mathrm{Mg}$ pressed into pellets was used, and $\mathrm{Mg}$ foil which was cut into pieces and was sanded to remove the oxide layer. The anodes were tested in the presence of electrolytes TG, Hi, and PEG6000 (Fig. 6). Due to the bad capacity and performance of electrolyte PEO, it was chosen to omit it from further testing.

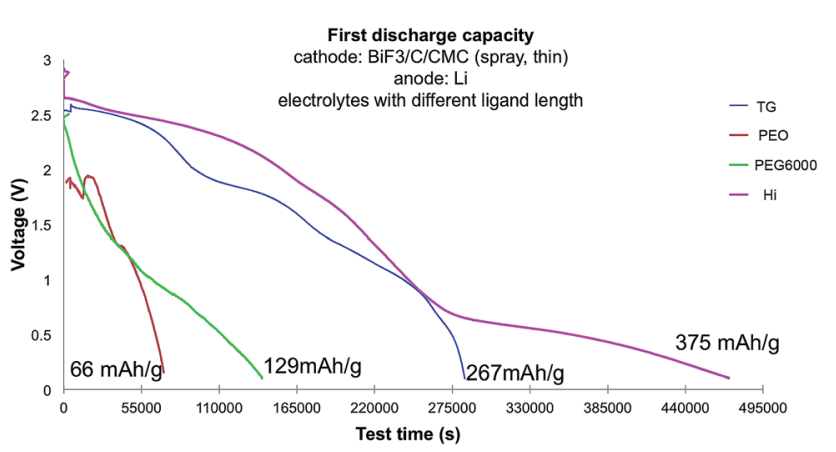

Fig. 6 Discharge capacities versus electrolyte. Comparison of the first discharge capacities of cells using electrolytes of different lengths with $\mathrm{BIF}_{3} / \mathrm{CMC} / \mathrm{C}$ cathodes and lithium anodes (the capacities are not constant and can easily show variation of $\pm 50 \mathrm{~mA} \mathrm{~h} \mathrm{~g} \mathrm{~g}^{-1}$, typical discharge curve and capacities were chosen for this figure). 
Discharge curves with different electrolytes against $\mathrm{Mg}$ foil and $\mathrm{Mg}$ pellets

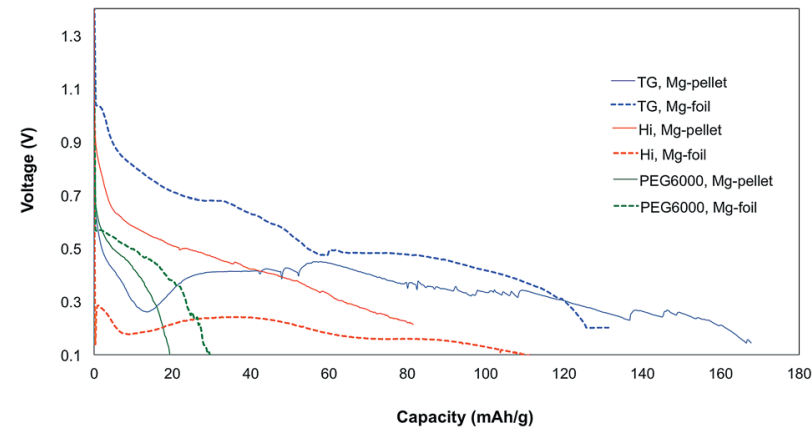

Fig. 7 Discharge capacities versus anode configuration. Discharge performance with $\mathrm{Mg}$ pellet or foil anodes as a function of electrolyte (the capacities are not constant and can easily show variation of \pm 30 $\mathrm{mA} \mathrm{h} \mathrm{g}{ }^{-1}$, typical discharge curve and capacities were chosen for this figure).

The $\mathrm{Mg}$ anodes did not perform as well as $\mathrm{Li}$ in the discharge tests, with capacities decreased by approximately half. The pressed $\mathrm{Mg}$ pellets showed better performance than the $\mathrm{Mg}$ foil and both liquid electrolytes TG and Hi were far better than with electrolyte PEG6000 (Fig. 7). In electrolyte TG, a capacity up to $160 \mathrm{~mA} \mathrm{~h} \mathrm{~g}^{-1}$ was observed for the $\mathrm{Mg}$ pellet. Electrolyte PEO, with the longest ligand chain length, showed the poorest results with a capacity under $30 \mathrm{~mA} \mathrm{~h} \mathrm{~g}{ }^{-1}$. Once again, capacity differences for the replicates of each cell were experienced, however, the general trends were unchanged, and both liquid electrolytes showed far better performance than the best results with PEG6000.

None of the discharge curves showed a very smooth line and variation in the voltage can typically be observed. This could have several reasons, starting from chemical side reactions with the electrodes or the electrolytes, as wells as problems with other parts of the batteries (see chapter separator). Unfortunately, similarly to the lithium anode reference cell, only one cycle was achieved in most cases. The $\mathrm{Mg}$ anodes were therefore investigated by SEM to determine if $\mathrm{a} \mathrm{MgF}_{2}$ passivation layer had formed.

\section{Mg anodes and passivation}

The SEM images of the discharged anodes were remarkably different from the pristine anodes (Fig. 8).

Snowflake-like formations, or even a large crust, covering the original anode could be observed (ESI $\dagger$ ). The particles are sticking to the surface but do not grow into the anode material, as shown by ablation with a focus ion beam of the anode surface (Fig. 8, lower right picture). Energy-dispersive X-ray spectroscopy (EDX) of the surface showed the presence of fluorine. The presence of fluorine in the white "flakes" (ESI $\dagger$ ) was detected, and it is suggested that these flakes are indeed $\mathrm{MgF}_{2}{ }^{{ }^{13}}$ The presence of fluorine on the $\mathrm{Mg}$ foil could also be confirmed by EDX (ESI $\dagger)$.

Intriguingly the $\mathrm{Mg}$-foil anodes generally showed a much heavier crust formation.
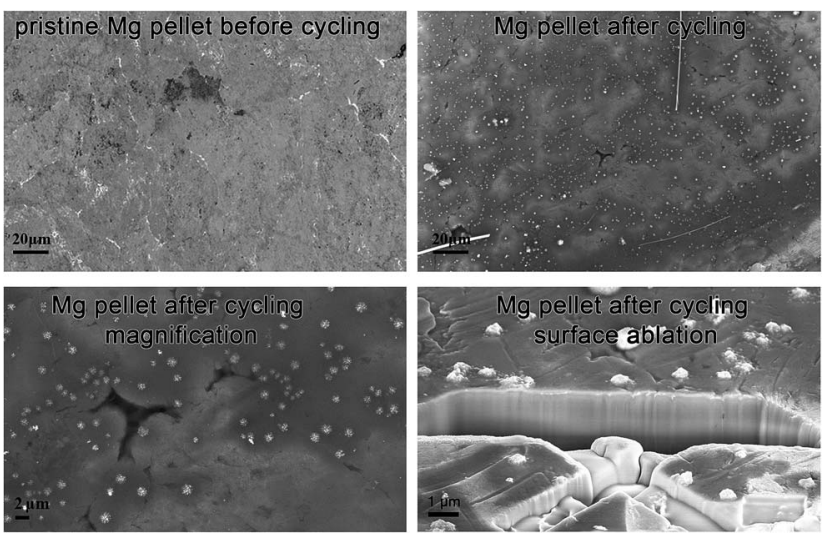

Fig. 8 SEM images of anodes. Before and after SEM images of $\mathrm{Mg}$ anodes after battery discharge tests. Mg pellets pristine (upper left photo), and after cycling (upper right photo). With magnification of the particles (lower left photo) and with surface ablation (lower right photo).

Next, the possibility of using composite electrodes made of $\mathrm{Mg} / \mathrm{MgF}_{2}$ was examined. It is known that such a system can improve the conductivity of $\mathrm{F}^{-}$in comparison to pure $\mathrm{Mg}$ or pure $\mathrm{MgF}_{2} \cdot{ }^{14}$ Such electrodes have been tested successfully in solid-state FiB systems and showed better performance than conventional $\mathrm{Mg}$ pellets. ${ }^{5}$ Based on this information, two new composite anodes were prepared, the first being a mixture of $\mathrm{Mg}$ and $\mathrm{MgF}_{2}$. In the second, a composite of $\mathrm{Mg}$ and $\mathrm{KF}$ was used, with the intention of achieving a more negative reduction potential by using the more electropositive K. Unfortunately, for our liquid battery systems, the capacities were not improved whatsoever using these composite anodes (Fig. 9). The discharge capacities were much worse than the normal $\mathrm{Mg}$ anodes.

The SEM images of the $\mathrm{Mg} / \mathrm{MgF}_{2}$ composite as well as $\mathrm{Mg} / \mathrm{KF}$ do not show any major differences between the reference and cycled anodes (Fig. 10). This leads us to conclude that almost no reaction had taken place on the anode side.

The final anode we examined was a material comprised of a mixture of $\mathrm{Mg}$ and polyaniline (PANI) emeraldine base. There is

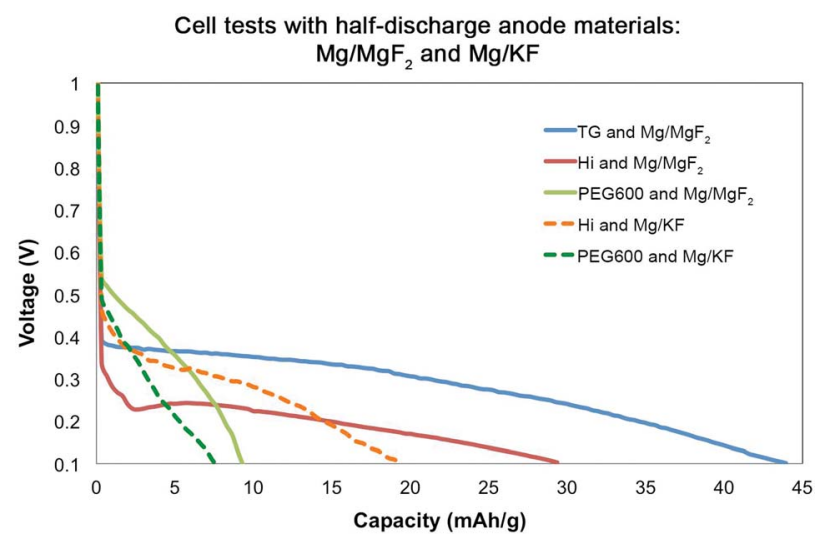

Fig. 9 Discharge capacities against $\mathrm{Mg}$ composite anodes. The capacity decreases if the $\mathrm{Mg} / \mathrm{MgF}_{2}$ or $\mathrm{Mg} / \mathrm{KF}$ composite systems are used. 

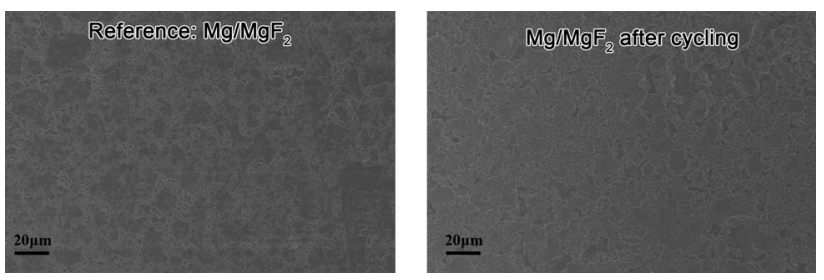

Fig. $10 \mathrm{SEM}$ images of the $\mathrm{Mg} / \mathrm{MgF}_{2}$ composite anode before and after cycling.

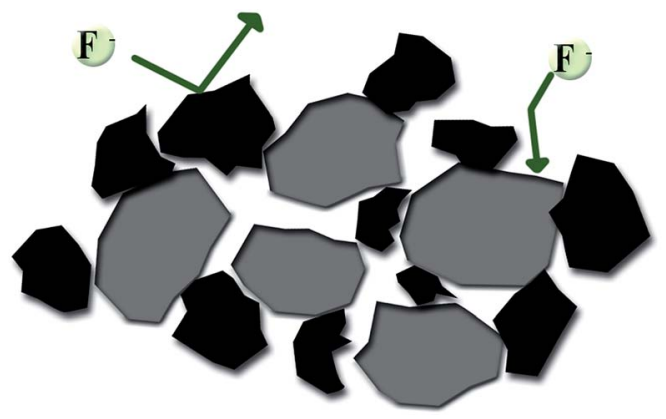

Fig. 11 Proposed deactivation of $\mathrm{Mg}$ anode. Schematic illustration of the coating of the grey $\mathrm{Mg}$ particles by a layer of inactive material, such as PANI.

evidence that PANI can intercalate fluoride ions. ${ }^{14}$ In using it, we hoped to achieve better conductivity, ${ }^{15,16}$ increase the reactivity beyond the surface of the electrode, and avoid crust formation. The PANI base was selected instead of the chloride-containing PANI emeraldine salt to avoid chloride or other halogen contamination. Magnesium powder was ball milled with PANI and shaped into the anode by pressing. Upon testing, the discharge was even worse than before (ESI $\dagger$ ), possibly because the PANI polymer coated the $\mathrm{Mg}$ particles and only a fraction of the "active" $\mathrm{Mg}$ was accessible to the electrolyte (Fig. 11). We suppose that this was also the reason why the mixed $\mathrm{Mg} / \mathrm{MgF}_{2}$ and $\mathrm{Mg} / \mathrm{KF}$ systems do not perform as well as anticipated: the

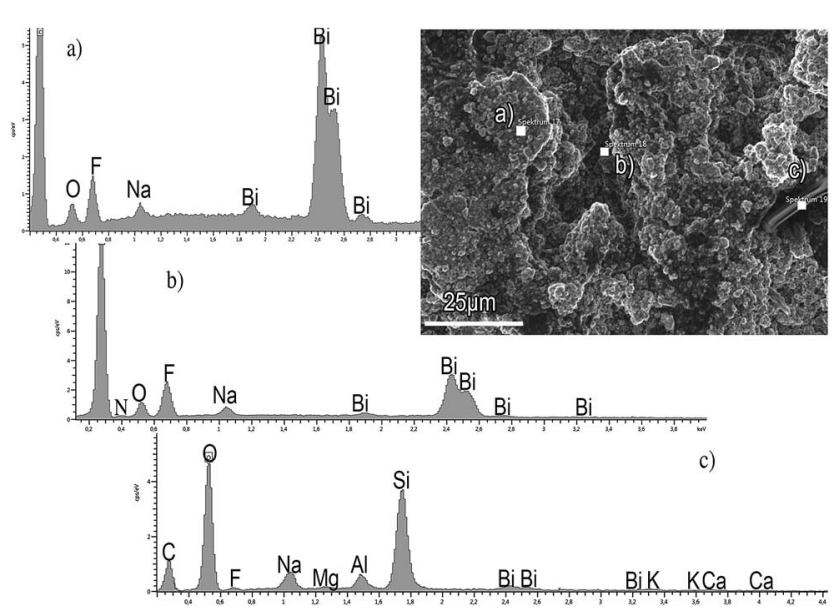

Fig. 12 EDX measurement of the surface of a discharge $\mathrm{BiF}_{3}$-cathodes, at different places.
$\mathrm{Mg}$ particles are covered and protected by a layer of an inactive material.

\section{Leaching of the separator}

In FiBs that use lithium as the anode, it has been observed that under certain circumstances, Li ions could migrate into the electrolyte and lead to erroneous capacity readings. ${ }^{1}$ Therefore, the issue of $\mathrm{Mg}$ migration into the electrolyte and deposition at the cathode, as well as the possible impact of impurities leached from the separator fibers was carefully investigated.

Under normal cycling conditions $\left(0.1 \mathrm{~V}, 1 \times 10^{-5} \mathrm{~A}\right)$, no $\mathrm{Mg}$ deposits were typically observed on the cathode surface. However, weak peaks from $\mathrm{Na}$ (from the binder), $\mathrm{Si}$, and $\mathrm{Al}$ were observed on almost all the cathodes after discharge. $\mathrm{Mg}$ was also occasionally detected by EDX, especially when pieces of the separator were close to the data collection points. Furthermore, traces of $\mathrm{Ba}, \mathrm{K}$, and $\mathrm{Ca}$ were also observed. A separate EDX measurement of the separator showed that these alkaline (earth) metals, in addition to other elements, are present on the aluminosilicate separator (ESI $\dagger$ ), and can leach into the electrolyte (Fig. 12).

The potential for leaching was assessed by soaking the fibers (15 mg) in $0.3 \mathrm{~mL}$ of water for $24 \mathrm{~h}$. The solution was examined by inductively coupled plasma-optical emission spectrometry (ICP-OES), which revealed the leaching of $\sim 3 \mathrm{ppm} \mathrm{Mg}$ and $13 \mathrm{ppm}$ Na. To test whether impurities from the separator could have an impact on the discharge capacity, a test similar to that described in ref. 1 was performed. The electrolyte was replaced by pure solvent (higlyme or tetraglyme) and cycling tests were performed immediately after cell assembly and also after $20 \mathrm{~h}$ of resting time. The as-prepared batteries failed completely, and no capacity could be observed. We conclude, therefore, that the presence of such small amounts of $\mathrm{Mg}$ or even alkaline earth metals will not have any impact on battery performance or afford erroneous capacity results.

\section{Outlook}

To overcome this leaching problem further battery tests were done with different separators. Three systems were chosen: (a) thin celluloses paper (b) polyurethane sponge (c) thick interwoven cellulose material.

The polyurethane sponge and the thick cellulose separators could take up a larger amount of electrolyte (about $0.3 \mathrm{~mL}$ ) and can act as an electrolyte tank. The cell tests were done with electrolyte TG under the standard conditions (Fig. 13).

The OCV for each of the three separators was around $1.2 \mathrm{~V}$ and dropped to $0.7 \mathrm{~V}$ for the thick cellulose material, $0.5 \mathrm{~V}$ for the polyurethane sponge and to $0.3 \mathrm{~V}$ for the thin cellulose paper separator as soon as the discharge started. The capacity was clearly better than the one with the standard separator and could reach up to $250 \mathrm{~mA} \mathrm{~h} \mathrm{~g}{ }^{-1}$ for the polyurethane sponge material and for the thick cellulose material, while the

$\ddagger$ The active material of the battery discharged with thick cellulose materials was 2 $\mathrm{mg}$ and not $1 \mathrm{mg}$ as we used for others tests. 


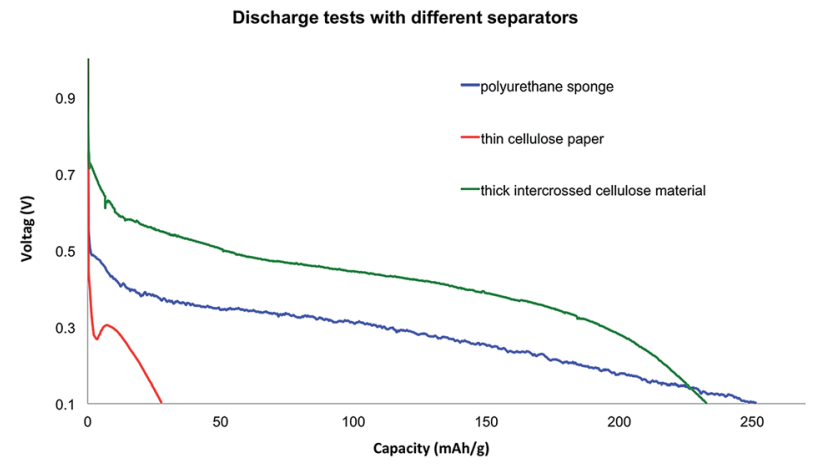

Fig. 13 Discharge curves of $\mathrm{BiF}_{3}$ against $\mathrm{Mg}$ with three different separators.

celluloses paper separator shows a poorer capacity of only about $30 \mathrm{~mA} \mathrm{~h} \mathrm{~g}{ }^{-1}$. The curves are much smoother without voltage variation.

This shows how sensitive the RT-FiB are towards changes of only one parameter and that each part of the battery needs to be considered for testing.

Ongoing research will also focus on the use of different metal anodes and other fluoride salts for cathode materials. To better understand the process in the RT-FiB further electrochemical investigations as well as new electrolyte designs are in process.

\section{Experimental}

\section{General}

All reactions were carried out under standard laboratory conditions in air. Acetonitrile (MeCN) and dimethylcarbonate (DMC) for electrolyte preparation were dried and stored over molecular sieves. The cell assembly was performed under inert conditions in a glovebox to avoid moisture. ${ }^{1} \mathrm{H}$ and ${ }^{19} \mathrm{~F}$ NMR spectra were acquired on a Bruker $500 \mathrm{MHz}$ Ultrashield and a Bruker $400 \mathrm{MHz}$ spectrometer with $\mathrm{CDCl}_{3}$ or $\mathrm{D}_{2} \mathrm{O}$ as solvent. FTIR spectra were collected on a Perkin-Elmer Spectrum Two spectrometer. TGA-differential scanning calorimetry (DSC) was measured on a Mettler Toledo TGA/SDTA 851. Viscosity was measured on a Thermo Haake Mars Rheometer. X-ray powder diffractograms were recorded on a Stadi P diffractometer (STOE \& Cie GMBH) with a MYTHEN detector using $\mathrm{Cu} \mathrm{K} \alpha$ radiation. Higlyme - a blend of small liquid PEG oligomers containing highly ethoxylated diethers of a high-molecular-weight alcohol—was purchased from BASF.

\section{Electrolyte preparation}

The electrolytes were prepared in a manner similar to that reported in ref. 1 with some modification.

Tetraglyme $\cdot \mathbf{N H}_{\mathbf{4}} \mathbf{F}_{2} \mathbf{H}$, compound TG. Tetraethylene glycol $(3 \mathrm{~g}, 0.13 \mathrm{mmol})$ and ammonium bifluoride $(0.7 \mathrm{~g}, 0.13 \mathrm{mmol})$ were stirred and heated at $80{ }^{\circ} \mathrm{C}$ for $3 \mathrm{~h}$. The reaction mixture was allowed to cool, and then acetonitrile $(\mathrm{MeCN}, 40 \mathrm{~mL})$ was added. The solution was heated at reflux for $5 \mathrm{~h}$, and then stirred at room temperature for another $12 \mathrm{~h}$. After filtration to remove unreacted ammonium bifluoride, the solvent was evaporated at reduced pressure. Before use as an electrolyte, the colorless liquid was dried in vacuo.

IR (ATR, $\mathrm{cm}^{-1}$ ): $2877 \mathrm{~b}, 1739 \mathrm{vw}, 1456 \mathrm{w}, 1352 \mathrm{w}, 1303 \mathrm{w}$, $1250 \mathrm{w}, 1200 \mathrm{~m}, 1101 \mathrm{~s}, 1029 \mathrm{~m}, 991 \mathrm{vw}, 948 \mathrm{w}, 853 \mathrm{~m}, 551 \mathrm{~b} .{ }^{1} \mathrm{H}$ NMR $\left(\mathrm{CDCl}_{3}, \mathrm{ppm}\right): 3.66$ (glycol units, $\left.10 \mathrm{H}\right), 3.55\left(\mathrm{CH}_{3} \mathrm{OCH}_{2}\right.$, $4 \mathrm{H}), 3.39\left(\mathrm{CH}_{3}, 6 \mathrm{H}\right) .{ }^{19} \mathrm{~F}$ NMR $\left(\mathrm{CDCl}_{3}, \mathrm{ppm}\right):-152.27,-152.32$ $\left(\mathrm{F}_{2} \mathrm{H}\right)$. TGA: evaporation and decomposition from $135{ }^{\circ} \mathrm{C}$ until $204{ }^{\circ} \mathrm{C}$. Viscosity: $0.0043 \mathrm{~Pa}$ s at $20^{\circ} \mathrm{C}$.

Higlyme $\cdot \mathrm{NH}_{4} \mathbf{F}_{2} \mathbf{H}$, compound $\mathrm{Hi}$. The same procedure was followed as for compound $\mathbf{1}$, using higlyme ( $3 \mathrm{~g}$, about 0.006 mmol) ammonium bifluoride $(0.5 \mathrm{~g}, 0.008 \mathrm{mmol})$, and $\mathrm{MeCN}$ $(40 \mathrm{~mL})$. A slightly thicker liquid than compound 1 was obtained.

IR (ATR, $\mathrm{cm}^{-1}$ ): $2926 \mathrm{~m}, 2858 \mathrm{~m}, 1739 \mathrm{vw}, 1456 \mathrm{w}, 1352 \mathrm{w}$, $1303 \mathrm{w}, 1250 \mathrm{w}, 1107 \mathrm{~s}, 951 \mathrm{w}, 855 \mathrm{w}, 725 \mathrm{vw} .{ }^{1} \mathrm{H}$ NMR $\left(\mathrm{CDCl}_{3}\right.$, ppm): $3.65,3.61-3.54,3.45,3.38,1.57,1.26,0.88 .{ }^{19} \mathrm{~F}$ NMR $\left(\mathrm{CDCl}_{3}, \mathrm{ppm}\right):-152.31,-152.36\left(\mathrm{~F}_{2} \mathrm{H}\right)$. TGA: evaporation and decomposition from $130{ }^{\circ} \mathrm{C}$ until $360{ }^{\circ} \mathrm{C}$. Viscosity: 0.0195 Pa s at $20^{\circ} \mathrm{C}$.

Poly(ethylene oxide)600 000 $\cdot \mathrm{NH}_{4} \mathrm{~F}_{2} \mathrm{H}$, compound PEO. PEO600 000 ( $1 \mathrm{~g}, 0.0016 \mathrm{mmol})$ and a large excess of ammonium bifluoride $(0.095 \mathrm{~g}, 1.6 \mathrm{mmol})$ were dissolved in MeCN $(40 \mathrm{~mL}$; a few millilitres of methanol can be added to obtain better dissolution of the ammonium bifluoride). The reaction solution was heated to reflux for $5 \mathrm{~h}$ and filtered to remove unreacted ammonium bifluoride. The solvent was evaporated and the remaining plastic-like polymer film was dried in vacuo.

IR (ATR, $\mathrm{cm}^{-1}$ ): $3250 \mathrm{bw}, 2887 \mathrm{~s}, 2750 \mathrm{w}, 1466 \mathrm{~m}, 1359 \mathrm{w}$, $1341 \mathrm{~s}, 1303 \mathrm{w}, 1280 \mathrm{~m}, 1242 \mathrm{w}, 1149 \mathrm{w}, 1097 \mathrm{~s}, 1081 \mathrm{~s}, 961 \mathrm{~s}, 841$ s, $750 \mathrm{w}, 530 \mathrm{~m} .{ }^{1} \mathrm{H}$ NMR $\left(\mathrm{CDCl}_{3}\right.$, ppm): 3.65 (glycol units). ${ }^{19} \mathrm{~F}$ NMR ( $\left.\mathrm{CDCl}_{3}, \mathrm{ppm}\right)$ : -152.35 (very weak $\mathrm{F}_{2} \mathrm{H}$ peak). TGA: first weight loss observed at $211{ }^{\circ} \mathrm{C}$ to $357{ }^{\circ} \mathrm{C}(-17 \%)$, followed by decomposition from $357^{\circ} \mathrm{C}$ to $427^{\circ} \mathrm{C}$.

Methylated PEG6000 $\cdot \mathrm{NH}_{4} \mathrm{~F}_{2} \mathrm{H}$, compound PEG6000. This material was prepared following the method in ref. 1 with slight modifications, as described for compound $\mathbf{1}$.

\section{Electrode preparation}

Cathode preparation. Generally, the cathode materials were mixed in a ball mill and milled for 10 cycles, with 10 min milling times at $250 \mathrm{rpm}$ and $20 \mathrm{~min}$ rests. Acetylene carbon black was used as carbon source. For the $\mathrm{BiF}_{3} / \mathrm{C} / \mathrm{PVDF}$ slurry $(0.7 \mathrm{~g} / 0.2 \mathrm{~g} /$ $0.1 \mathrm{~g}$ ), about $0.2 \mathrm{~g}$ of the mixture was dissolved in just enough $N$-methylpyrrolidone (NMP) to obtain a smooth slurry and coated by hand on a stainless steel collector. For the $\mathrm{BiF}_{3} / \mathrm{C} /$ CMC $(0.7 \mathrm{~g} / 0.2 \mathrm{~g} / 0.1 \mathrm{~g})$ solution intended for spray coating, the mixture $(0.4 \mathrm{~g})$ was slurried in a few millilitres of water and then diluted to $30 \mathrm{~mL}$. Stainless collectors were heated to $140{ }^{\circ} \mathrm{C}$ and the coating was sprayed on, layer by layer, until a coating weight of around $1 \mathrm{mg}$ was reached. Before use in a battery cell, the cathode was dried overnight in a vacuum oven at $100^{\circ} \mathrm{C}$.

Anode preparation. The composite $\mathrm{Mg} / \mathrm{MgF}_{2}$ electrode was prepared by ball milling equivalent amounts of each material ( $0.5 \mathrm{~g}$ eq.) under Ar over 6 cycles at $250 \mathrm{rpm}$ with $10 \mathrm{~min}$ milling times and $20 \mathrm{~min}$ rests. All anodes were pressed into pellets in a glovebox under inert conditions to avoid the formation of an oxide layer on the $\mathrm{Mg}$ surface. The $\mathrm{Mg} / \mathrm{KF}$ electrode was 
prepared similarly. The final electrode, $\mathrm{Mg} /$ polyaniline emeraldine base, was prepared by ball milling a mixture of $\mathrm{Mg}$ powder, particle size $<0.1 \mathrm{~mm}(0.8 \mathrm{~g})$ and polyaniline emeraldine base $\left(0.2 \mathrm{~g}, M_{\mathrm{w}}=50000\right)$ under the same conditions as above and pressing into pellets.

\section{Conclusions}

It was demonstrated that our new liquid electrolytes based on tetraglyme and higlyme performed better than the solid electrolyte based on the PEG matrix with longer glycol chains. We were also able to show that fluoride batteries can be discharged using magnesium anodes, and that the method of cathode preparation has a significant impact on the overall capacity. The most efficient cathode preparation was achieved by spraycoating the stainless steel collector with the cathode material. It was possible to improve our cathode in a sustainable way by using non-toxic CMC and water instead of PVDF and NMP. Examination of the cathode by EDX determined that the separator, which contained alkaline earth and alkali metal ions with the potential for leaching, could pose a significant problem. Nevertheless, it was showed that these impurities did not contribute additional capacity to the batteries.

Unfortunately, cycling could not be achieved in these batteries due to the formation of a $\mathrm{MgF}_{2}$ layer on the surface of the $\mathrm{Mg}$ anode. An attempt to solve this problem was made by using $\mathrm{Mg} / \mathrm{MgF}_{2}, \mathrm{Mg} / \mathrm{KF}$ or $\mathrm{Mg} / \mathrm{PANI}$ composite anodes, however this proved unsuccessful. Further tests were done using different separators and showed that sponge like materials out of polyurethane significantly increased the discharge capacity.

Therefore we conclude that the multiparametric tests brought many insights into issues and problems of RT-FiB and we demonstrated a few options to avoid these problems and increase the performance of such batteries.

\section{Acknowledgements}

The authors would like to thank Carola Hoffmann-Richter from the University Ulm for the TGA measurement, Ute Golla-
Schindler and Jörg Bernhard for help with SEM/EDX measurements and Daniel Sandbeck for research assistance.

\section{Notes and references}

1 F. Gschwind, Z. Zhao-Karger and M. Fichnter, J. Mater. Chem. A, 2014, 2, 1214-1218.

2 C. Rongeat, M. A. Reddy, R. Witter and M. Fichtner, J. Phys. Chem. C, 2013, 117, 4943.

3 M. A. Reddy and M. Fichtner, J. Mater. Chem., 2011, 21, 17059-17548.

4 I. Darolles, C. M. Weiss, M. M. Alam, A. Tiruvannamalai and S. C. Jones, US Pat., US2012/0164541 A1, 2012.

5 G. G. Amatucci and N. Pereira, J. Fluorine Chem., 2007, 128, 243-262.

6 C. Rongeat, M. Anji Reddy, T. Diemant, R. J. Behm and M. Fichtner, J. Mater. Chem. A, 2014, 2, 20861-20872.

7 W. Baukal, Electrochim. Acta, 1974, 19, 687-693.

8 (a) M. E. Wilson, K. Peach, W. J. Zhou and M. J. Kurth, J. Org. Chem., 1998, 63, 5094-5099; (b) D. J. Buckley, M. Berger and D. Poller, J. Polym. Sci., 1962, 56, 163-174.

9 (a) A. Marquez, J. Uribe and R. Cruz, J. Appl. Polym. Sci., 1997, 21, 2221-2232; (b) A. Carrilo, I. R. Martin-Dominguez, A. Rosas and A. Marquez, Polymer, 2002, 43, 6307-6313.

10 B. R. Lee and E. S. Oh, J. Phys. Chem. C, 2013, 117, 4404-4409.

11 J. Li, R. B. Lewis and J. R. Dahn, Electrochem. Solid-State Lett., 2007, 10(2), A17-A20.

12 A. Guerfi, M. Kaneko, M. Petitclerc, M. Mori and K. Zaghib, J. Power Sources, 2007, 163, 1047-1052.

13 Magnesium Technology 2003 Proceedings, ed. K. Aarstad, G. Tranell, G. Pettersen, T. A. Engh and H. I. Kaplan, TMS, Warrendale, PA.

14 H. Cui, Q. Li, Y. Qian, R. Tang, H. An and J. Zhai, Water Res., 2011, 45, 5736-5744.

15 A. G. MacDiarmid, J. C. Chiang, A. F. Richter and A. J. Epstein, Synth. Met., 1987, 18, 285-290.

16 A. A. Syed and M. K. Dinesan, Talanta, 1991, 8, 815-837. 